\title{
SCORE TO ASSESS THE RISK OF PNEUMONIA IN CORONAVIRUS DISEASE-19
}

Dear Editor,

We would like to share ideas on the publication, "Development of Simple and Sensitive Score to Assess the Risk of Pneumonia in Coronavirus disease (COVID-19) Patients"1. Hormanstorfer et al. concluded that "This sensible score may improve the risk stratification of COVID-19 patients in the pre-hospital setting"1. Indeed, the attempt to develop a new scoring system or model for predicting COVID-19 infection or its severity is interesting. The important point is the

\section{REFERENCES}

1. Hormanstorfer M, Ragusa MA, Poggio L, Moreira-Facundo J, Orellana-Villa Z, Bobrowski FA, et al. Development of simple and requirement for further validation test on the new system internationally. We would like to draw attention to a possible underlying confounding factor that can result in decreasing ability of risk assessment of the new system. In a setting where there is a high rate of underlying chest disease, such as Asian countries, there is an elevated rate of patients with silent underlying chest disease. For example, a COVID-19 infection might simultaneously occur with pulmonary tuberculosis $^{2}$. The new score system might not be applicable in those cases.

sensitive score to assess the risk of pneumonia in COVID-19 patients. Rev Invest Clin. 2020;73 [Epub ahead of print].

2. Yasri S, Wiwanitkit V. Tuberculosis and novel Wuhan Coronavirus infection: pathological interrelationship. Indian J Tuberc. 2020;67:264.

\section{SORA YASRI ${ }^{1 *}$ AND VIROJ WIWANITKIT ${ }^{2}$}

${ }^{1}$ Private Academic Consultant, Bangkok, Thailand; ${ }^{2}$ Honoray Professor, Dr DY Patil University, Pune, India

${ }^{*}$ Corresponding author:

Sora Yasri

E-mail: sorayasri@outlook.co.th
Received for publication: 21-10-2020

Approved for publication: $30-10-2020$

DOI: $10.24875 /$ RIC.20000503

0034-8376 / @ 2020 Revista de Investigación Clínica. Published by Permanyer. This is an open access article under the CC BY-NC-ND license (http://creativecommons.org/licenses/by-nc-nd/4.0/). 


\section{AUTHORS' REPLY}

Dear Editor,

We have read and appreciate the comments made by Yasri and Wiwanitkit on our article, "Development of Simple and Sensitive Score to Assess the Risk of Pneumonia in Coronavirus disease (COVID-19) Patients"1. We agree that patients with an underlying lung disease (e.g., tuberculosis) may have respiratory symptoms that do not belong to COVID-19, leading to unnecessary chest images when applying the score. Regarding this comment, we believe it is important to mention that the score was developed in Argentina, a country

\section{REFERENCES}

1. Hormanstorfer M, Ragusa MA, Poggio L, Moreira-Facundo J, Orellana-Villa Z, Bobrowski FA, et al. Development of simple and also with a high prevalence of underlying silent chest disease, and thus, this population is not under-represented in our cohort. We also believe that the realization of chest images in those patients could help to differentiate COVID-19 from other diseases. For example, the high-resolution CT pattern of COVID-19 is relatively specific (peripheric subpleural ground glass opacities) and distinguishable from COPD or tuberculosis. Consequently, the risk of misdiagnosis is, in our opinion, reasonably low. However, we agree that the existence of a previously undiagnosed respiratory disease represents a clinical scenario in which our score can fail, and thus could be considered a weakness of the clinical prediction rule.

\section{Macarena Hormanstorfer* and Francisco Paulin}

Internal Medicine, Hospital Juan A. Fernández, Buenos Aires, Argentina

*Corresponding author:

Macarena Hormanstorfer

E-mail: hormanstorferm@gmail.com
Received for publication: 30-10-2020

Approved for publication: 02-11-2020

DOI: 10.24875/RIC.M20000005 